\title{
"Chicago Classification" Should Be Challenged in the Diagnosis of Achalasia: Heterogeneity of Achalasia
}

TO THE EDITOR: We read with interest the review article by Lee et $\mathrm{al}^{1}$ regarding "Clinical characteristics and treatment outcomes of 3 subtypes of achalasia according to the Chicago classification in a tertiary institute in Korea." The study showed that type II achalasia ( $\mathrm{n}=28[50.9 \%])$ is the most common subtype followed by type I $(\mathrm{n}=21[38.2 \%])$ and type III $(\mathrm{n}=6$ [10.9\%]). Interestingly, all type III patients responded to calcium channel blocker in the study. The authors suggested that type III should be a different entity from those of type I and II. We strongly agree with their opinion. We have been evaluating patients with suspected achalasia using high-resolution manometry (HRM) with special interest for 5 years. To our experi- ence, the definition of achalasia according to "Chicago classification of HRM" is not perfect. We have experienced achalasia patients with normal integrated relaxation pressure (IRP). As one example, a 12-year-old female who began to experience dysphagia for solid food approximately 2 months before presentation. Physical examination did not reveal signs of scleroderma. Upper endoscopy revealed esophageal dilatation with retained secretion and food material (Fig. 1A and 1B). A barium esophagogram showed severe disturbance in emptying into the stomach (Fig. 1C). HRM at sitting position showed aperistalsis with normal 4 second-IRP (normal range $<15 \mathrm{mmHg}$ ) (Fig. 1D). Eckardt score at that time was 5. Based on this con-
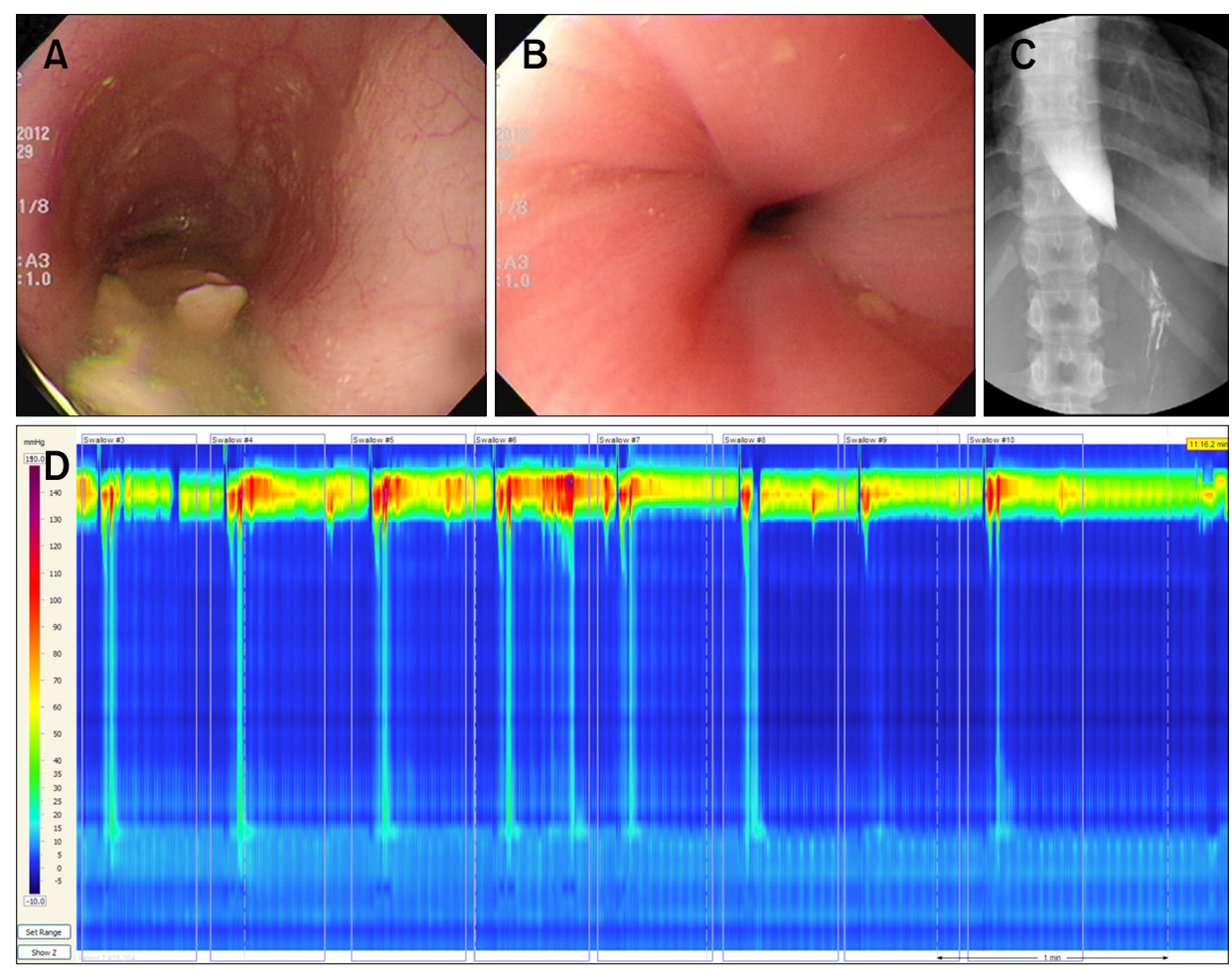

Figure 1. Clinical findings of a 12 -yearold female with solid dysphagia. (A) Upper endoscopy shows dilated esophagus and retained food material. (B) Lower esophageal sphincter is not opened with air inflation. (C) Esophageal dilatation with bird-beak narrowing of the esophagogastric junction is noted on the barium esophagogram. (D) High-resolution manometry reveals aperistalsis with normal 4 second-integrated relaxation pressure $(3.9 \mathrm{mmHg})$. 

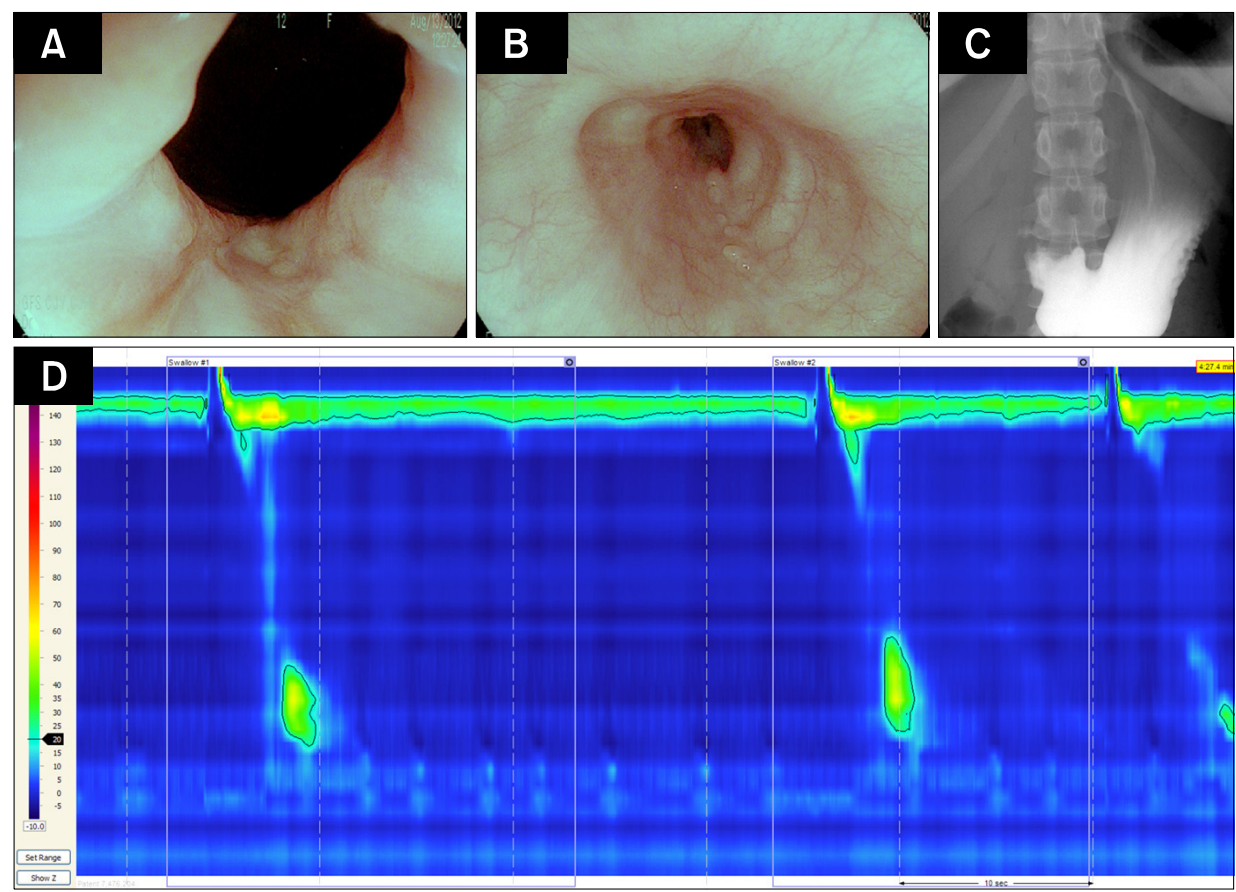

Figure 2. The clinical findings of followup at 6 months after peroral endoscopic myotomy. (A) Upper endoscopy shows opened lower esophageal sphincter. (B) A scar is visible at the site of the mucosal entrance. (C) Barium esophagogram shows free flow of contrast from the esophagus to the stomach. (D) Highresolution manometry reveals weak peristalsis.

stellation of data, the patient was diagnosed with achalasia, and underwent peroral endoscopic myotomy. On follow-up at 6 months, she was free of dysphagia, and upper endoscopy revealed unremarkable findings except for scar changes at the site of the mucosal entrance (Fig. 2A and 2B). Barium esophagography showed free flow of contrast from the esophagus to the stomach (Fig. 2C). HRM showed weak peristalsis with large peristaltic defects (Fig. 2D).

The Chicago classification is challenged by this case of achalasia with normal IRP. In fact, we have experienced 4 patients with achalasia, who were similar to this case. These findings suggested that normal IRP does not preclude a diagnosis of achalasia. Refining the IRP should be needed especially in patients with low lower esophageal sphincter (LES) pressure, although the sitting position might contribute to these atypical findings. Earlier studies of conventional manometry demonstrated that a subset of achalasia patients had apparently normal LES relaxation. ${ }^{2-5}$ In the past, one plausible explanation for the reason is that it represents an artifact from the movement of manometry catheter. In the era of HRM, the achalasia cases with normal LES relaxation (ie normal IRP) can not be explained by the artifact associated with catheter movement. The findings of achalasia with normal IRP also raise a number of issues regarding the etiopathogenesis of achalasia. The findings might be a representative of an early phase of the achalasia. The relatively short period follow-up (2 months) may support this possible expla- nation. Interestingly, this case showed transition from achalasia to weak peristalsis after treatment. In conclusion, we should know the significance in the heterogeneity of achalasia, that is not addressed by current "Chicago classification of HRM."

Tae Hee Lee ${ }^{1}$ and Su Jin Hong ${ }^{2}$ ${ }^{I}$ Institute for Digestive Research, Soonchunhyang University, College of Medicine, Seoul, Korea; and ${ }^{2}$ Department of Internal Medicine, Soonchunhyang University, College of Medicine, Bucheon,

Gyeonggi-do, Korea

1. Lee JY, Kim N, Kim SE, et al. Clinical characteristics and treatment outcomes of 3 subtypes of achalasia according to the Chicago classification in a tertiary institute in Korea. J Neurogastroenterol Motil 2013;19:485-494.

2. Mearin F, Malagelada JR. Complete lower esophageal sphincter relaxation observed in some achalasia patients is functionally inadequate. Am J Physiol Gastrointest Liver Physiol 2000;278:G376-G383.

3. Kim JH, Rhee PL, Lee SS, et al. Is aperistalsis with complete lower esophageal sphincter relaxation an early stage of classic achalasia? J Gastroenterol Hepatol 2007;22:536-541.

4. Katz PO, Richter JE, Cowan R, Castell DO. Apparent complete lower esophageal sphincter relaxation in achalasia. Gastroenterology 1986;90:978-983.

5. Hirano I, Tatum RP, Shi G, Sang Q, Joehl RJ, Kahrilas PJ Manometric heterogeneity in patients with idiopathic achalasia. Gastroenterology 2001;120:789-798.

\section{Conflicts of interest: None.}

